Canadian Journal of Fisheries and Aquatic Sciences

Canadian

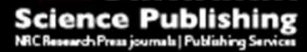
Journal canadien des sciences halieutiques et aquatiques

\title{
Habitat features mediate selective consumption of salmon by bears
}

\begin{tabular}{|r|l|}
\hline Journal: & Canadian Journal of Fisheries and Aquatic Sciences \\
\hline Manuscript ID & cjfas-2017-0055.R1 \\
\hline Danuscript Type: & Article \\
\hline $\begin{array}{r}\text { Complete List of Authors: } \\
\text { Is the invited manuscript for } \\
\text { consideration in a Special } \\
\text { Issue? : }\end{array}$ & $\begin{array}{l}\text { Andersson, Luke; Simon Fraser University, Biological Sciences } \\
\text { Seynolds, John D.; Simon Fraser University, Department of Biological }\end{array}$ \\
\hline Keyword: & $\begin{array}{l}\text { PREDATOR-PREY INTERACTION < General, NUTRIENTS < General, } \\
\text { RIPARIAN < Environment/Habitat, SALMON < Organisms, BEAR }\end{array}$ \\
\hline &
\end{tabular}

SCHOLARONE

Manuscripts 


\section{Habitat features mediate selective consumption of salmon by bears}

\section{Authors}

3 Luke C. Andersson,

4 Earth to Ocean Research Group, Simon Fraser University, Department of Biological

5 Sciences, 8888 University Dr., Burnaby, BC V5A 1S6

6 lukeandersson@gmail.com

8 John D. Reynolds,

9 Earth to Ocean Research Group, Simon Fraser University, Department of Biological

10 Sciences, 8888 University Dr., Burnaby, BC V5A 1 S6

11 reynolds@sfu.ca

\section{Corresponding Author:}

14 Luke C. Andersson, Simon Fraser University,

15 Department of Biological Sciences, 8888 University Dr., Burnaby, BC V5A 1 S6

16 lukeandersson@gmail.com, Ph: 778.782 .5610 ext. 3989, Fax: n/a 


\section{Abstract}

Salmon provide a key source of marine-derived nutrients to aquatic and surrounding

19 terrestrial habitats in coastal areas of the North Pacific. Bears are a major predator of salmon

20 and provide an important pathway for carcass transfer to riparian zones. We studied selective

21 consumption of salmon (Oncorhynchus keta and O. gorbuscha) by bears (Ursus arctos and $U$.

22 americanus) on 12 streams on the central coast of British Columbia, Canada. We predicted

23 bears would select more energy-rich parts, and eat less of each fish (i.e., selective

24 consumption), in streams with more prey and simpler habitat (i.e., streams that facilitate salmon

25 capture). Bears were $12 \%$ more likely to consume fish selectively in narrow, shallow streams

26 with less pool volume, where salmon are easier to catch, than in deep, wide streams. However,

27 bears were also $21 \%$ more likely to selectively consume fish in streams with more wood

28 obstacles and undercut banks, where hunting was predicted to be more difficult. This suggests

29 that stream characteristics can have significant indirect effects on riparian nutrient subsidies to

30 ecosystems through selective feeding by bears. 


\section{Introduction}

Pacific salmon (Oncorhynchus spp.) are an important source of cross-boundary, marine-

33 derived nutrient delivery to North Pacific coastal ecosystems. Salmon spend most of their lives

34 growing in the sea, before migrating to their natal freshwater streams to spawn. After spawning,

35 they die and deliver valuable nutrients to surrounding aquatic and terrestrial ecosystems

36 (Schindler et al. 2003; Helfield and Naiman 2006). Foraging bears facilitate salmon nutrient

37 transfer to terrestrial habitats, as they pull live fish out of streams and leave their carcasses on

38 land nearby (Hilderbrand et al. 1999; Quinn et al. 2009). Once a salmon carcass is abandoned

39 by a bear, the remains become available to a suite of other species (e.g., insects and

40 scavenging birds) that transfer nutrients (reviewed in Gende et al. 2002 and Janetski et al.

41 2009). These nutrients are also incorporated into surrounding plant matter (Hocking and

42 Reynolds 2011; Hocking and Reynolds 2012), and can have impacts on local breeding bird

43 communities (Christie and Reimchen 2008, Field and Reynolds 2011)

Carcasses left in the riparian zone are particularly important to nutrient transfer because

45 they are less likely to be washed downstream into the estuary than the senescent salmon which

46 die in the streams (Cederholm et al. 1989). Even bear-killed salmon abandoned within streams

47 have more value, in nutrient terms, than senescent salmon carcasses, for certain species. For

48 example, caddisfly (Trichoptera) larvae preferentially colonize bear-killed salmon due to

49 increased temporal availability, energetic content and accessibility of tissue (Winder et al. 2005).

50 The amount of salmon biomass abandoned by bears is, therefore, an important component to

51 overall nutrient transfer to both terrestrial and aquatic pathways.

52 To understand the patterns of salmon consumption by bears, we turn to classical

53 foraging theory to ask: when should bears stop eating a given carcass and invest the additional 
54 time and energy required to catch a new one? A variant on the classical patch model of

55 foraging theory (Charnov 1976) by Sih (1980) treats each prey item as a patch and each bite as 56 a choice. The decision to abandon a partially eaten carcass depends on the diminishing rate of 57 return from continuing to eat a fish after the most energy-rich parts have been consumed versus 58 investing time and energy in catching a new fish. This framework predicts that bears should be 59 more selective for energy-rich parts of salmon in streams where fish are easier to catch.

60 Reimchen (2000) and Gende et al. (2001) demonstrated a preference by bears for high-energy

61 tissues such as the brain and eggs. The ease with which bears can catch salmon should

62 depend on habitat characteristics that offer refuge and escape opportunities for the fish, such as

63 wide, deep streams with large pools, wood obstacles and undercut banks (Gende et al. 2004b,

64 Braun and Reynolds 2011, Andersson and Reynolds, 2017). Furthermore, bears kill more

65 salmon, up to a density-dependent asymptote (Quinn et al. 2003; Quinn et al. 2016), and are

66 more selective for energy-rich parts (Gende et al. 2001) at higher salmon spawning

67 abundances. Though individual behaviour may vary from bear to bear, we predict that these

68 patterns will, generally, be observed across a large number of streams over a full salmon 69 spawning season.

Selective consumption patterns by bears may also differ with the sex and species of

71 prey as well as the date in the salmon spawning season. Because of their eggs, females have

72 a higher caloric value per total mass than males (Hendry and Berg 1999, Gende et al. 2004a),

73 which means bears would need to consume more of each male to acquire similar energetic

74 rewards. Chum are larger than pink salmon, with estimated masses of $3.5 \mathrm{~kg}$ and $1.2 \mathrm{~kg}$,

75 respectively (Hocking and Reynolds 2011). Therefore, eating an equal amount of biomass of

76 each, before abandonment of the carcass, would result in a lower proportion of consumption of

77 a chum salmon carcass than of a pink salmon carcass. Furthermore, it may be easier to

78 selectively remove and consume energy-rich parts of larger size-classes of salmon because 
79 their bodies could allow for more handling dexterity, manoeuvrability and precision of brain

80 removal by bears (Reimchen 1994). Selective consumption patterns may also change through

81 the fall because bears enter hyperphagia, a pre-hibernation stage associated with substantially

82 increased appetite leading to daily caloric intake increases from $8000 \mathrm{kcal}$ to $20000 \mathrm{kcal}$, at

83 some point in the salmon spawning season (Nelson 1980; Nelson et al. 1983). Moreover, the

84 energy quality of salmon flesh and quantity of eggs decreases through the season (Hendry and

85 Berg 1999; Reimchen 2000). As the number and quality of salmon decreases toward the end of

86 the spawning period, bears may need to eat more of each kill to acquire similar energy rewards

87 and meet their energetic requirements.

Our objectives were to compare the consumption of salmon carcasses by bears among streams and to quantify relationships with spawning salmon abundance and stream characteristics. We predicted that the proportion of bear-killed salmon that show evidence of

91 selective tissue consumption would be: 1) higher in streams with greater prey abundance, 2)

92 higher in streams with less wood, undercut banks, pools and water volume (i.e. possible refuge

93 for prey), 3) higher on chum salmon than pink, and 4) higher earlier in the salmon spawning

94 season (Table 1). Our prediction of more selective consumption earlier in the season was less

95 confident as there is conflicting evidence for brain preferences based on spawning status of the

96 salmon. Reimchen (2000) demonstrated that bears would more often selectively consume the

97 brains of early-stage spawning salmon, and reject the brains of the more spawned-out fish,

98 whereas Frame (1974) noted a preference for the brains of spawned-out salmon. Therefore,

99 our predictions are based on the preference for eggs (Gende et al. 2001) and presence of more

100 pre-spawned, egg-filled salmon earlier in the spawning season than at the end when the

101 population shifts to more spawned-out salmon showing signs of senescence. Thus, if all else

102 were equal, we predicted higher selective consumption patterns at the start of the season than

103 at the end. Predictions relating to salmon sex are also less clear: bears could be more selective 
104 when eating females if they target eggs and discard the rest of the carcass, or they could be 105 less selective because females are smaller than males. We studied 12 streams in a remote 106 region along the central coast of British Columbia, Canada, where human disturbance to 107 habitats is minimal. The results reveal how patterns in bear consumptive behaviour may be 108 influenced by hunting difficulty caused by physical attributes of the stream, with consequences 109 for the amount of biomass left in the riparian zone, local food webs, and overall nutrient transfer 110 in the ecosystem.

\section{Methods}

113 Rainforest on the central coast of British Columbia, Canada (Fig. 1). Stream characteristics 114 were measured in the summer of 2014 and salmon counts and measurements took place during 115 the salmon spawning season in the fall of 2014. We were not able to quantify the number of 116 bears at each stream. Black bears (Ursus americanus) are found throughout the region, 117 whereas grizzly bears (U. arctos) are usually limited to the 4 mainland streams. Exploratory 118 analyses did not reveal any differences in trends (e.g. number of kills, predation rate and 119 selective consumption) between the mainland and the island streams.

\section{Stream characteristics}

Streams were divided into representative study reaches, which were sampled using a

122 stratified random sampling design. Each stream's study reach began where the stream met the 123 estuary. From that point we measured the bankfull width of the stream in 3 equidistant locations 124 and calculated the total reach length as 30 times the average bankfull width (Bain and 
125 Stevenson 1999). Bankfull width is the maximum width that water could reach in the channel 126 before flooding over the banks. Each reach was separated into 4 equidistant sections and 3 127 transects were assigned randomly per section, totalling 12 transects per reach.

At the reach level, we measured total pool volume per $100 \mathrm{~m}$, total volume of wood per $100 \mathrm{~m}$, and percent of reach with undercut banks according to standard practices (Bain and

130 Stevenson 1999). All qualifying wood (diameter $>0.1 \mathrm{~m}$ and length $>1.5 \mathrm{~m}$ within the stream 131 banks) was measured and a total volume was calculated per $100 \mathrm{~m}$ to normalize for differing 132 reach lengths. These streams had no obvious bottlenecks or ledges caused by large woody 133 debris that may make hunting easier at those locations. Pool dimensions (i.e., width, length, 134 maximum depth and tail depth) were measured for all pools (Fausti et al. 2004). Tail depth (i.e. 135 depth at downstream riffle crest) is the deepest part of the downstream portion of the pool. 136 Residual pool volumes were calculated using maximum depth minus tail depth, to account for 137 differences in water volumes of pools, as water levels will vary by the amount of recent rainfall, 138 and then standardized per $100 \mathrm{~m}$ (Lisle 1987). Transect level measurements included bankfull 139 width and channel height which both standardize for fluctuating water levels, with varying 140 rainfall, over the measurement season and represent stream size better than a single water 141 level measurement. There is variability in flow in each stream with rainfall but given the close 142 proximity of the streams we make the assumption that the size of the streams varies together in 143 wet or dry conditions and, thus, the stream rankings for size remains the same. Furthermore, 144 even the largest streams, during highest flows, were accessible and therefore did not 145 completely protect salmon from hunting (as would be the case in a large river where fish could 146 take refuge in the centre). All stream locations and characteristics are presented in Table 2. 


\section{Salmon characteristics}

Each site was visited 3 times throughout the salmon spawning season (between 11

149 September and 21 October, 2014) to quantify patterns of consumption of salmon. A thorough

150 search of the measured stream reach, as well as a 5-m band of the riparian zone on both

151 banks, was conducted to locate bear-killed salmon. We recorded the sex, species, and

152 consumptive patterns of each fish. Sex was determined by examining the gonads or, if absent,

153 we examined the jaw/snout, teeth, skin colouration and other sexually dimorphic characteristics

154 that readily distinguish the sexes. A categorical spawning status was assigned to each salmon

155 carcass based on a visual inspection of the skin condition, colouration, quantity of eggs, caudal

156 fin damage and other visible decay. The spawning status categories were: 1) pre-spawned, 2)

157 partially spawned, 3) post-spawned, and 4) heavily decomposed. These "decomposed"

158 individuals were not included in the analysis because heavy decay and scavenging or

159 colonization by maggots made it impossible to quantify consumptive choices by bears or

160 categorize spawning status of the fish at the time of consumption. Furthermore, we excluded

161 measurements of wolf-killed salmon, which are distinguished by their clean, surgical removal of

162 the brain case and abandonment of the rest of the carcass (Darimont et al. 2003). These kills

163 were usually in highly localized regions of estuaries at low tide, rather than along the stream in

164 the forest where we were working. Bear-killed salmon with selective consumption of the brain

165 were identified by their less-surgical removal of the brain, which often damaged the snout, eyes

166 and surrounding tissue (Reimchen 1994) and by the consumption patterns on the surrounding

167 salmon carcasses. We marked each measured carcass by cutting off the tip of the lower jaw to

168 avoid re-measurement on the next visits. 
169

\section{Selective consumption scoring systems}

Each carcass was assigned binary categorical values based on the amount of consumption (i.e., whether or not the majority of dorsal and trunk musculature was consumed) and type of body parts consumed (i.e., eggs, brain). A carcass was considered selectively consumed if the eggs (in females) and/or brain (both sexes) were consumed and $<50 \%$ of the overall carcass was consumed (i.e., there was a demonstrated selectivity for the energy-rich parts and abandonment of majority of the catch). Alternatively, if the energy-rich parts had been eaten but more than $50 \%$ of the fish was consumed or if the energy-rich parts had not been consumed then no selectivity for energy-rich parts had occurred.

we also tried an alternative analysis with a different response variable: 1 ) $<50 \%$ of salmon consumed = "selective" consumption, and 2) $>50 \%$ of salmon consumed = "non-selective" consumption. That is, we removed the requirement of consumption of an energy-rich part from the response variable and just focused on how much of the carcass was eaten. We used the same statistical methods as for the original models. The results for this model competition are included in the supplementary material and are similar, overall, to the mail results. Though salmon may be scavenged days after the initial kill (Quinn and Buck, 2000), we are still confident in our two scoring systems because scavenging rates can be low (Gende et al. 2004a), and our observation of the decomposition status of each carcass allowed us to analyse the results with the freshest kills removed (to verify that the results weren't skewed by bears scavenging these carcasses and removing significantly more flesh after our visits). Furthermore, we are still able to make inferences about how much flesh is left on the banks and to the riparian zone after both initial consumption and scavenging. 
192 210 timings of both species were relatively equal across most streams and therefore this mismatch 211 is negligible. Out of twelve streams, the proportion of chum salmon to total salmon peaked at 212 our middle count in six streams, decreased in one stream, increased in two streams and could 213 not be calculated for three streams were count occurrences were too low.

\section{Spawning salmon abundance}

members of our research group in conjunction with the Heiltsuk First Nation and personnel from Fisheries and Oceans Canada. We used visual estimation of live spawning salmon as well as counts of all senescent and bear-killed salmon located in the stream and within a 5 meter band on each bank. When 3 counts were achieved, the area-under-the-curve (AUC) estimation method was used to determine the total number of spawning salmon per stream (English et al. 1992). The spawning abundance at streams with fewer than 3 counts was determined using the peak live + dead estimation method. This method is highly correlated with AUC estimation in previous studies that examined streams in this area (Field \& Reynolds, 2011; Hocking \& Reynolds 2011), and was confirmed to be a close match in the study streams (chum salmon AUC mean= $1172.6 \pm 337$, chum peak mean=1 423.1 $\pm 421.92, r=0.962, p<0.001, n=7$ streams; pink salmon AUC mean= $1874.8 \pm 845.17$, pink peak mean=1859.0 $\pm 976.26, r=$ 0.996, $p<0.001, n=5$ streams). We combined pink and chum salmon, to calculate "total prey abundance", representing the total number of salmon per stream available to bears. This reduced the number of parameters in our models and accounted for the issue of collinearity between pink and chum salmon abundances. A mismatch in timing of pink and chum salmon runs could complicate analyses especially with respect to the date variable. However, the run 


\section{Statistics and modelling}

Statistical analyses were performed with R (version 3.2.2; R Project for Statistical

216 Computing, Vienna, Austria). We competed generalized linear mixed effects models (GLMMs),

217 with a binomial response and logit link, using Akaike's Information Criterion $\left(\mathrm{AIC}_{\mathrm{c}}\right)$, corrected for

218 small sample size. The models describe the probability of selective consumption of each bear-

219 killed salmon under varying conditions of prey susceptibility (i.e., stream complexity) and

220 abundance. Mixed-effects models account for a lack of independent samples at the stream

221 level in the study design. We compared 5 models to evaluate the relative support for each

222 hypothesis (Table 3). Care was taken to limit the number of hypotheses to a priori, biologically

223 feasible models in order to avoid spurious findings from testing large "all-subsets" models

224 (Burnham and Anderson 2002).

In order to deal with collinearity and reduce the number of parameters in our models, we created reduced sets of linearly uncorrelated variables through principal components analysis (PCA). This method extracts orthogonally-linear sets of "principal components" with minimal loss of information and eliminates co-linearity between variables (Graham 2003). A PC named "cover" was created to combine wood volume/100 $\mathrm{m}$ and percentage of bank that is undercut

230 since these features were positively correlated and are both predicted to offer shelter in the form

231 of hiding and escape opportunities for spawning salmon (Deschênes and Rodríguez 2007;

232 Braun and Reynolds 2011). The first principal component explained $77 \%$ of the variance with both variables loading $>0.71$. Another PC named "escape" was created in a separate analysis

234 to combine the positively correlated and hydro-geologically related variables: pool volume/100 $235 \mathrm{~m}$, bankfull width, and channel height. These variables represent water quantity, which is 236 associated with escape opportunities for spawning salmon along with lowered visibility for 237 hunting bears (Fukushima \& Smoker, 1998; Gende et al., 2004b). The first principal component 
238 for "escape" explained $72.5 \%$ of the variance and all variables loaded $>0.57$.

239 The response variable was binomially distributed with $0=$ "non-selective" and $1=$ 240 "selective" consumption. The global model was as follows:

$241 \quad(1)$

$$
Y_{i} \sim \operatorname{Bin}\left(1, p_{i}\right)
$$

242

$$
\operatorname{logit}\left(p_{i}\right)=\beta_{0}+\beta_{1} \text { sex }_{i}+\beta_{2} \text { species }_{i}+\beta_{3} \text { date }_{i}+\beta_{4} \text { cover }_{i}+\beta_{5} \text { escape }_{i}+\beta_{6} \text { abundance }_{i}+a_{i}
$$

$243(3)$

$$
a_{i} \sim N\left(0, \sigma_{a}^{2}\right)
$$

244 where logit stands for the logistic link, $p_{i}$ is the probability that a carcass was selectively 245 consumed for energy-rich parts, $\beta_{0}$ is the intercept and $\beta$ is a vector that regulates each 246 estimable parameter's contribution to the probability of selective consumption. Habitat 247 complexity (i.e., cover and escape indices) and salmon abundance are fixed, centered, scaled 248 continuous variables (Schielzeth 2010). Sex, species, and date were included in all models, 249 except the null model, as forced parameters to control for possible differences in predator 250 preferences per type of fish (i.e., due to inherent differences in the amount of flesh and energy251 rich parts) or over time in the season. These parameters would also account for differences in 252 sex and species ratios between streams and differences in the sampling date among sites. ai is 253 included as a random intercept, by stream, to control for variability at the stream level and 254 account for a lack of independent sampling within streams. The random intercept is assumed to 255 be normally distributed with mean 0 and variance $\sigma_{a}^{2}$ and accounts for the lack of information 256 about bear abundance or other inherent differences in streams that are not accounted for in the 257 model (Zuur et al. 2009). Variance Inflation Factors (VIF) for each of the models were all less 
258 than 2, which confirms that the model parameters did not have a multicollinearity issue (Zuur et 259 al. 2010).

260 Results

Bears selectively consumed $31 \%$ of all carcasses examined across the 12 streams

262 ( $n=659)$, with a higher proportion of selective consumption of females $(38.6 \%)$ than males

$263(20 \%)$, and more on chum (35.7\%) than pink salmon (25.4\%). In species by gender subgroups,

264 selective consumption occurred on $31.2 \%$ of pink females, $15.3 \%$ of pink males, $44.6 \%$ of chum

265 females and $23.7 \%$ of chum males.

As predicted, selective consumption was higher at narrower, shallower streams with

267 fewer pools (i.e., low escape index) but, contrary to our predictions, selective consumption was

268 higher at streams with more wood obstacles and undercut banks (i.e., high cover index) (Fig. 2).

269 The bivariate plots revealed no obvious trends in selective consumption over time in the season

270 nor with the number of spawning salmon (Fig. 2). The top model in the $\mathrm{AIC}_{\mathrm{c}}$ competition was the

271 habitat complexity model which includes the escape index, cover index and the forced

272 parameters of sex, species and date (Table 3).

273 The probability plots generated from the top model's predictions further confirmed that

274 bears selectively consumed salmon more frequently in narrower, shallower streams with fewer

275 pools, and in streams with more wood and undercut banks (Fig. 3). These plots illustrate the

276 top model's predicted probabilities of selective consumption, holding all other parameters

277 constant at their means. The predicted probability of selective consumption is higher for

278 females than males, and on chum salmon than on pink (Fig. 3). Sex, species and date were

279 included as forced parameters to control for possible differences in patterns with these 
280 variables. There is some uncertainty in the date and escape index parameter estimates, which

281 both have 95\% confidence intervals that overlap zero (Fig. 4). This uncertainty is reduced

282 considerably under the alternative scoring system (supplementary material) which is the more

283 relevant measure in terms of implications for nutrient transfer.

The results for the alternative scoring system for selective consumption, based only on

285

286

287

288

289

290

the amount of flesh eaten, were similar to the original scoring system, including bivariate plots

(Fig. S1), AlC competition (Table S1), and probability plots (Fig. S2). The only exceptions were a reversal of the effect of sex, whereby males had a higher probability of being consumed selectively $(48 \%)$ than females $(41 \%)$ as well as a stronger effect for date, which has parameter coefficient estimates that do not overlap zero, and escape and cover indices (Fig. S3).

\section{Discussion}

These results confirm our prediction that bears would feed more selectively on salmon that they caught on smaller streams (i.e., narrower, shallower and with smaller pool volume), though the estimate of this effect carried some uncertainty. We were surprised to find that the opposite appears to be true of streams with less wood volume and fewer undercut banks, where bears tended to feed less selectively on each catch. We discuss these results in light of both the theory that generated the predictions and also the implications for the role of stream habitats and salmon abundance in mediating transfer of salmon-derived nutrients to riparian zones.

The finding that bears ate more of each salmon that they caught on larger streams is consistent with our prediction, based on the trade-off between continuing to consume a given carcass versus hunting for new fish, when hunting is more difficult. However, contrary to our predictions, bears were more likely to be selective in their feeding in streams with higher cover, 
302 where we assumed that hunting would be more difficult. This may be because bear's hunting

303 technique (e.g., chasing, wading/plunging, standing at waterfalls) may be determined by

304 topographic features (Luque and Stokes 1974; Klinka and Reimchen 2002; Gill and Helfield

305 2012) and may differ between "high cover" and "low cover" streams. If bears use these stream

306 features to their advantage to trap prey, it is possible that although wood and undercut banks

307 may decrease the visibility of individual prey, they do not necessarily protect them from capture.

308 If so, then the inability to target their desired prey before capture could lead to increased

309 selectivity in consumption after capture, which would explain the results for streams with high

310 cover. This explanation is supported by results in Andersson and Reynolds (2017) where bears

311 were less able to capture preferred larger, higher-quality salmon in streams with higher cover

312 over the same spawning period. In the same high cover streams where size-biased predation

313 was not occurring, bears caught more fish than at low cover streams (with sized-biased

314 predation), and consumed those kills more selectively (Andersson and Reynolds, 2017).

Contrary to our predictions, there was no relationship between selective consumption and the number of spawning salmon (Fig. 2). Furthermore, the number of salmon was included

317 in the $2^{\text {nd }}$ model which was an identical but more complex version of the top model, with little

318 additional explanatory power and, therefore, has no biologically interpretable effect (Arnold,

319 2010). Furthermore, in a post hoc analysis using salmon density instead of abundance, the

320 models were ranked in the same order and with similar weights as our original analysis (i.e., top

321 model: habitat complexity; $\mathrm{AIC}_{\mathrm{c}} \mathrm{w}_{i}=0.46$, second model: habitat complexity + density; $\mathrm{AIC}_{\mathrm{c}} w_{i}=$

322 0.23). This is inconsistent with our expectations from foraging theory (e.g. Charnov, 1976, Sih,

323 1980), and the findings of Gende et al. (2001) who demonstrated that bears selected more

324 energy-rich parts and consumed less of each fish in habitats and years with higher salmon

325 density. Abandoning a carcass in pursuit of new prey makes sense when prey are abundant 326 and easy to catch; low-quality parts can be left uneaten when a surplus of high-quality prey with 
327 high-quality parts is still widely accessible (e.g., Goss-Custard 1977). Perhaps the number of 328 spawning salmon was never low enough for bears to compensate in an obvious way by altering 329 their consumption patterns. We found that predation rates were relatively low at these streams, 330 ranging from $2.1 \%$ to $21.4 \%$ (Andersson and Reynolds, 2017).

We considered sex, species, and time of year because these all may influence selective consumption. Even though they were not directly competed in the model selection process

333 (except with the null model), these forced parameters were generally good predictors of 334 selective consumption. As predicted, bears were less selective in their consumption, and ate 335 more of each catch, as the season progressed. This effect was even clearer in the top model of 336 the analysis that used the alternative scoring system that considered total prey consumption, 337 rather than incorporating energy-rich tissues as part of the score (Fig. S3). Salmon have fewer 338 eggs and lower energy stores after spawning (Hendry and Berg 1999; Reimchen 2000) and 339 bears increase their caloric consumption at the end of the season (Nelson 1980). Salmon that 340 have spawned contain approximately half of the energetic value of pre-spawned salmon (Gilbert 341 and Lanner 1995) due to loss of musculature and gametes (Gende et al. 2004a) and generally 342 are not preferred (Gende et al. 2004b). Increased hunger, coupled with lower energy prey, may 343 cause bears to consume more of each carcass near the end of the season when this is all that 344 is available. We also found a higher probability of selective consumption when bears consumed 345 females rather than males. Eggs can comprise $20 \%$ of a female's body mass (Hendry and Berg 346 1999). We found that $89 \%$ of the females that were considered selectively consumed were 347 missing eggs whereas $49 \%$ were missing brains (these 2 are not mutually exclusive - many 348 carcasses were missing both). The alternative scoring system, which does not include energy349 rich parts, revealed that bears were more likely to eat the majority ( $>50 \%$ ) of a female carcass 350 than a male carcass, probably because females are smaller and, therefore, the same number of 351 bites on prey of each sex would result in a higher proportion of the carcasses of females being 
352 consumed. Finally, as predicted, bears were more likely to selectively consume chum than pink 353 salmon. This is also potentially due to the size difference. Additionally, our findings are 354 consistent with Reimchen's (1994) suggestion that it may be easier for bears to select for 355 energy-rich parts on larger fish (e.g., chum) due to the higher dexterity associated with handling 356 the larger prey.

Though we consider initial consumption of the carcass and scavenging to both be important factors in this consumption analysis (with the same consequences to nutrient transfer), it is possible that bears scavenged carcasses directly after our visits and, therefore, caused us to misidentify some carcasses as "selectively consumed" despite them being shortly thereafter scavenged and ending up as non-selectively consumed. To account for this, we ran a post hoc analysis using only bear-killed salmon in the later categories of decomposition. We assumed that bears would most likely return to scavenge the freshest kills after our visits so the killed fish with "decomposition level 0" were removed from the post hoc analysis. Habitat complexity continued to rank higher than the "density" and "density + habitat complexity models" (by similar weights). Furthermore, in the top model, the directionality of each of the model 367 coefficients was the same as the original top model and the magnitude of their effect was 368 similar. Size-biased predation (i.e., for larger prey) by bears can have significant impacts on the

370 flux of biomass to terrestrial ecosystems (Carlson et al. 2011) which can have significant 371 impacts on the abilities of scavengers to utilize the biomass (e.g. Meehan et al. 2005). We can

372 illustrate an analogous effect, due to selective consumption per fish, rather than selective 373 predation, by comparing 2 streams at each extreme of the cover index, based on the 374 probabilities of selective consumption (Fig. S2). The alternative scoring system, which 375 considers the amount of flesh eaten, not contingent on energy-rich parts, is more relevant when 
376 investigating terrestrial nutrient inputs. Holding date, escape index, sex and species parameters

377 constant at their means, approximately $60 \%$ of carcasses in streams with the highest cover

378 index will be consumed selectively whereas only approximately $30 \%$ of carcasses in streams

379 with the lowest cover index will be consumed selectively. In this calculation, we assume that

380 each chum salmon weighs $\approx 3.5 \mathrm{~kg}$, and each pink salmon, $\approx 1.2 \mathrm{~kg}$ (Hocking and Reynolds

381 2011). We further assumed that bears eat $1 / 4$ of each "selectively consumed fish" (i.e., the

382 ones that were $<50 \%$ consumed) and ate $3 / 4$ of each "non-selectively consumed" fish, which

383 was a typical observation. Thus, for every 100 chum and 100 pink salmon killed by bears at

384 each stream, the stream with highest cover index is subsidized with $192.5 \mathrm{~kg}$ (chum) $+66 \mathrm{~kg}$

$385($ pink $)=258.5 \mathrm{~kg}$ (total) of abandoned carcass biomass that remains uneaten by bears. The

386 stream with lowest cover is subsidized with $140 \mathrm{~kg}$ (chum) $+48 \mathrm{~kg}$ (pink) = $188 \mathrm{~kg}$ (total) of

387 abandoned carcass biomass. This represents a difference of $70.5 \mathrm{~kg}$ of salmon biomass, for

388 every 100 fish of each species killed, based only on the differences between the probabilities of

389 selective consumption in streams with little or a lot of wood and undercut banks. Further multi-

390 year studies in these streams that increase sample size, quantify patterns of carcass

391 distribution, predator waste excretion, and overall nutrient transfer would be valuable for

392 quantifying habitat-mediated nutrient transfer via predation and consumption.

393 This study contributes to our understanding of cross-boundary, nutrient-transfer

394 pathways and how they can be shaped by characteristics of the stream in conjunction with the

395 foraging behaviour of bears. Consideration of the behavioural ecology of predators thereby

396 helps us understand how nutrient subsidies reach aquatic and terrestrial habitats.

\section{Acknowledgements}


Funding for this research was provided by Simon Fraser University, the Natural

399 Sciences and Engineering Research Council of Canada (NSERC), the W. Garfield Weston

400 Foundation and the Tom Buell BC Leadership Chair endowment funded by the Pacific Salmon

401 Foundation and the BC Leading Edge Endowment Fund. We thank the Heiltsuk First Nation for

402 supporting this research and all those who assisted in data collection: Aaron Gaffney, Howard

403 Humchitt, Jane Pendray, Ben Rabinovich, Michelle Segal, Mary Vasey, Marlene Wagner,

404 Kirsten Wilcox and Ross Wilcox. We are grateful to the Earth to Ocean Research Group at

405 Simon Fraser University, and to Isabelle Côté and Larry Dill for valuable input in all stages of

406 this project. Finally, we thank Tom Quinn and an anonymous reviewer for suggestions that

407 greatly improved this paper.

408

\section{Literature Cited}

410 Arnold, T.W. 2010. Uninformative parameters and model selection using Akaike's information

411 criterion. J. Wildl. Manage. 74:1175-1178.

412 Bain, M.B., and Stevenson, N.J. 1999. Aquatic habitat assessment: common methods. American

413 Fisheries Society, Bethesda, M.D.

414 Andersson, L.C., and Reynolds, J.D. 2017. Effects of habitat features on size-biased predation on

415 salmon by bears. Oecologia. 184:101-114.

416 Braun, D.C., and Reynolds, J.D. 2011. Relationships between habitat characteristics and breeding

417 population densities in sockeye salmon (Oncorhynchus nerka). Can. J. Fish. Aquat. Sci. 68:758-67. 
418 Burnham, K.P., and Anderson, D.R. 2002. Model selection and multi-model inference. 2nd edition. 419 Springer-Verlag, New York, N.Y.

420 Carlson, S.M., Quinn, T.P., and Hendry, A.P. 2011. Eco-evolutionary dynamics in Pacific salmon. 421 Heredity 106:438-447.

422 Cederholm, C.J., Houston, D.B., Cole, D.L., and Scarlett, W.J. 1989. Fate of coho salmon 423 (Oncorhynchus kisutch) carcasses in spawning streams. Can. J. Fish. Aquat. Sci. 46:1347-55.

424 Charnov, E.L. 1976. Optimal foraging, the marginal value theorem. Theor. Popul. Biol. 9:129-36.

425 Christie, K.S. and Reimchen, T.E. 2008. Presence of salmon increases passerine density on Pacific 426 Northwest streams. Auk 125:51-59.

427 Cunningham, C.J., Ruggerone, G.T., and Quinn, T.P. 2013. Size selectivity of predation by brown 428 bears depends on the density of their sockeye salmon prey. Amer. Nat. 181:663-73.

429 Darimont, C.T., Reimchen, T.E., and Paquet, P.C. 2003. Foraging behaviour by gray wolves on 430 salmon streams in coastal British Columbia. Can. J. Zool. 81:349-53.

431 Deschênes, J., and Rodríguez, M.A. 2007. Hierarchical analysis of relationships between brook trout 432 (Salvelinus fontinalis) density and stream habitat features. Can. J. Fish. Aquat. Sci. 64:777-85.

433 English, K. K., Bocking, R. C., and Irvine, J. R. 1992. A robust procedure for estimating salmon 434 escapement based on the area-under-the-curve method. Can. J. Fish. Aquat. Sci. 49:1982-1989.

435 Fausti, K., Dugaw, D., Chambers, J., Dykstra, J., Sedell, T., Moyer, C., Lanigan, S., Anderson, A., 436 Archer, E., and Henderson R. 2004. Stream channel methods for core attributes. Effectiveness 437 monitoring for streams and riparian areas within the Pacific Northwest. Multi-federal Agency 
438 Monitoring Program, Logan, Utah, and Aquatic and Riparian Effectiveness Monitoring Program and 439 PACFISH/INFISH Biological Opinions (PIBO), Corvallis, O.R.

440 Field, R.D., and Reynolds, J.D. 2011. Sea to sky: impacts of residual salmon-derived nutrients on 441 estuarine breeding bird communities. Proc. R. Soc. Lond. [Biol] 278:3081-3088.

442 Floyd, T.A., Mclnnis, C., and Taylor, B.R. 2009. Effects of artificial woody structures on Atlantic 443 salmon habitat and populations in a Nova Scotia stream. River. Res. Appl. 25:272-82.

444 Frame, G.W. 1974. Black bear predation on salmon at Olsen Creek, Alaska. Z Tierpsychol. 35:2344538.

446 Fukushima, M., and Smoker, W.W. 1998. Spawning habitat segregation of sympatric sockeye and 447 pink salmon. Trans. Am. Fish. Soc. 127:253-60.

448 Gende, S.M., Edwards, R.T., Willson, M.F., and Wipfli, M.S. 2002. Pacific salmon in aquatic and 449 terrestrial ecosystems. BioScience 52:917-28.

450 Gende, S.M., Quinn, T.P., and Willson, M.F. 2001. Consumption choice by bears feeding on salmon. 451 Oecologia 127:372-82.

452 Gende, S.M., Quinn, T.P., Willson M.F., Heintz R., and Scott, T.M. 2004a. Magnitude and fate of 453 salmon-derived nutrients and energy in a coastal stream ecosystem. J Freshw Ecol 19:149-160.

454 Gende, S.M., Quinn, T.P., Hilborn, R., Hendry, A.P., and Dickerson, B. 2004b. Brown bears 455 selectively kill salmon with higher energy content but only in habitats that facilitate choice. Oikos $456 \quad 104: 518-28$. 
457 Gilbert, B.K., and Lanner, R.M. 1995. Energy, diet selection and restoration of brown bear

458 populations. International Conference on Bear Research and Management. French Ministry of the 459 Environment and the Natural History Museum of Grenoble, France 9:231-40.

460 Gill, I.D., and Helfield, J.M. 2012. Alternative foraging strategies among bears fishing for salmon: a 461 test of the dominance hypothesis. Can. J. Zool. 90:766-775.

462 Goss-Custard, J.D. 1977. The energetics of prey selection by redshank, Tringa tetanus (L.), in 463 relation to prey density. J. Anim. Ecol. 46:1-19.

464 Graham, M.H. 2003. Confronting multicollinearity in ecological multiple regression. Ecology $465 \quad 84: 2809-15$.

466 Helfield, J.M., and Naiman, R.J. 2006. Keystone interactions: salmon and bear in riparian forests of 467 Alaska. Ecosystems 9:167-80.

468 Hendry, A.P., and Berg, O.K. 1999. Secondary sexual characters, energy use, senescence, and the 469 cost of reproduction in sockeye salmon. Can. J. Zool. 77:1663-75.

470 Hilderbrand, G.V., Hanley, T.A., Robbins, C.T., and Schwartz, C.C. 1999. Role of brown bears 471 (Ursus arctos) in the flow of marine nitrogen into a terrestrial ecosystem. Oecologia 121:546-50.

472 Hocking, M.D., and Reynolds, J.D. 2011. Impacts of salmon on riparian plant diversity. Science $473 \quad 331: 1609-12$.

474 Hocking, M.D. and Reynolds, J.D. 2012. Nitrogen uptake by plants subsidized by Pacific salmon

475 carcasses: a hierarchical experiment. Can. J. Forest. Res. 42:908-917

476 Janetski, D.J., Chaloner, D.T., Tiegs, S.D., and Lamberti, G.A. 2009. Pacific salmon effects on

477 stream ecosystems: a quantitative synthesis. Oecologia 159:583-595. 
478 Klinka, D.R., and Reimchen, T.E. 2002. Nocturnal and diurnal foraging behaviour of brown bears 479 (Ursus arctos) on a salmon stream in coastal British Columbia. Can. J. Zool. 80:1317-1322

480 Lisle, T.E. 1987. Using 'residual depths' to monitor pool depths independently of discharge. Pacific 481 Southwest Forest and Range Experiment Station, Forest Service, U.S. Department of Agriculture, 482 Berkeley, C.A.

483 Luque, M. H., and Stokes, A. W. 1974. Fishing behaviour of Alaskan brown bear. In Bears-Their 484 Biology and Management: Proceedings of the Third International Conference on Bear Research and 485 Management, edited by M.R. Pelton, J.W. Lentfer, and G.E. Folk, 71-78. Binghamton, N.Y., 31 May $486-1$ June 1974, and Moscow, U.S.S.R., 11 June 1974. International Union for the Conservation of 487 Nature and Natural Resources, Morges, Switzerland.

488 MacArthur, R.H., and Pianka, E.R. 1966. On optimal use of a patchy environment. Amer. Nat. $489 \quad 100: 603-9$.

490 Meehan, E.P., Seminet-Reneau, E.E., and Quinn, T.P. 2005. Bear predation on Pacific salmon 491 facilitates colonization of carcasses by fly maggots. Am. Midl. Nat. 153:142-151.

492 Nelson, R.A. 1980. Protein and fat metabolism in hibernating bears. Fed. Proc. 39:2955-58.

493 Nelson, R.A., Folk, G.E. Jr., Pfeiffer, E.W., Craighead, J.J., Jonkel, C.J., and Steiger, D.L. 1983.

494 Behavior, biochemistry, and hibernation in black, grizzly, and polar bears. International Conference 495 on Bear Research \& Management 5:284-90.

496 Quinn, T.P., and Buck, G.B. 2001. Scavenging by brown bears, Ursus arctos, and glaucous-winged 497 gulls, Larus glaucescens, on adult sockeye salmon, Oncorhynchus nerka. Canadian Field-Naturalist $498 \quad 114: 217-223$. 
499 Quinn, T.P., and Buck, G.B. 2001. Size- and sex-selective mortality of adult sockeye salmon: bears, 500 gulls, and fish out of water. Trans. Am. Fish. Soc. 130:995-1005.

501 Quinn, T.P., and Kinnison, M.T. 1999. Size-selective and sex-selective predation by brown bears on 502 sockeye salmon. Oecologia 121:273-82.

503 Quinn T.P., Wetzel L., Bishop S., Overberg K., Rogers D.E. 2001. Influence of breeding habitat on 504 bear predation and age at maturity and sexual dimorphism of sockeye salmon populations. Can. J. 505 Zool. 79:1782-1793.

506 Quinn, T.P., Gende, S.M., Ruggerone, G.T., and Rogers, D.E. 2003. Density-dependent predation 507 by brown bears (Ursus arctos) on sockeye salmon (Oncorhynchus nerka). Can. J. Fish. Aquat. Sci. $508 \quad 60: 553-62$.

509 Quinn, T.P., Carlson, S.M., Gende, S.M., and Rich, H.B. Jr. 2009. Transportation of Pacific salmon 510 carcasses from streams to riparian forests by bears. Can. J. Zool. 87:195-203.

511 Quinn T.P., Cunningham C.J., Wirsing, A.J. 2016. Diverse foraging opportunities drive the functional 512 response of local and landscape-scale bear predation on Pacific salmon. Oecologia. 183:415-429

513 R: A Language and Environment for Statistical Computing. 2015. R. Core Team, R Foundation 514 for Statistical Computing. http://www.r-project.org/.

515 Reimchen, T.E. 1994. Further studies of predator and scavenger use of chum salmon in stream and 516 estuarine habitats at Bag Harbour, Gwaii Haanas. Queen Charlotte City.

517 Reimchen, T.E. 2000. Some ecological and evolutionary aspects of bear-salmon interactions in 518 coastal British Columbia. Can. J. Zool. 78:448-57. 
519 Roni, P., and Quinn, T.P. 2001. Density and size of juvenile salmonids in response to placement of 520 large woody debris in Western Oregon and Washington streams. Can. J. Fish. Aquat. Sci. 58:28252192.

522 Schielzeth, H. 2010. Simple means to improve the interpretability of regression coefficients. Methods 523 Ecol. Evol. 1:103-13.

524 Schindler, D.E., Scheuerell, M.D., Moore, J.W., Gende, S.M., Francis, T.B., and Palen, W.J. 2003.

525 Pacific salmon and the ecology of coastal ecosystems. Front. Ecol. Environ. 1:31-37.

526 Sih, A. 1980. Optimal foraging: partial consumption of prey. Amer. Nat. 116:281-90.

527 Winder, M., Schindler, D.E., Moore, J.W., Johnson, S.P, and Palen, W.J. 2005. Do bears facilitate 528 transfer of salmon resources to aquatic macroinvertebrates? Can. J. Fish. Aquat. Sci. 62:2285-93.

529 Zuur, A.F., leno, E.N., Walker, N.J., Saveliev, A.A., and Smith, G.M. 2009. Mixed effects models and 530 extensions in ecology with R. Edited by M. Gail, K. Krickeberg, J. M. Samet, A. Tsiatis, and W. 531 Wong. Springer, New York, New York.

532 Zuur, A.F., leno, E.N., and Elphick, C.S. 2010. A protocol for data exploration to avoid common 533 statistical problems. Methods Ecol. Evol. 1:3-14. 
537 Table $1 \quad$ Models, variables, mechanisms and predictions for original scoring and alternative scoring systems for selective consumption of salmon by bears. A null model and a model that compared only forced variables (sex, species and date) are not shown.

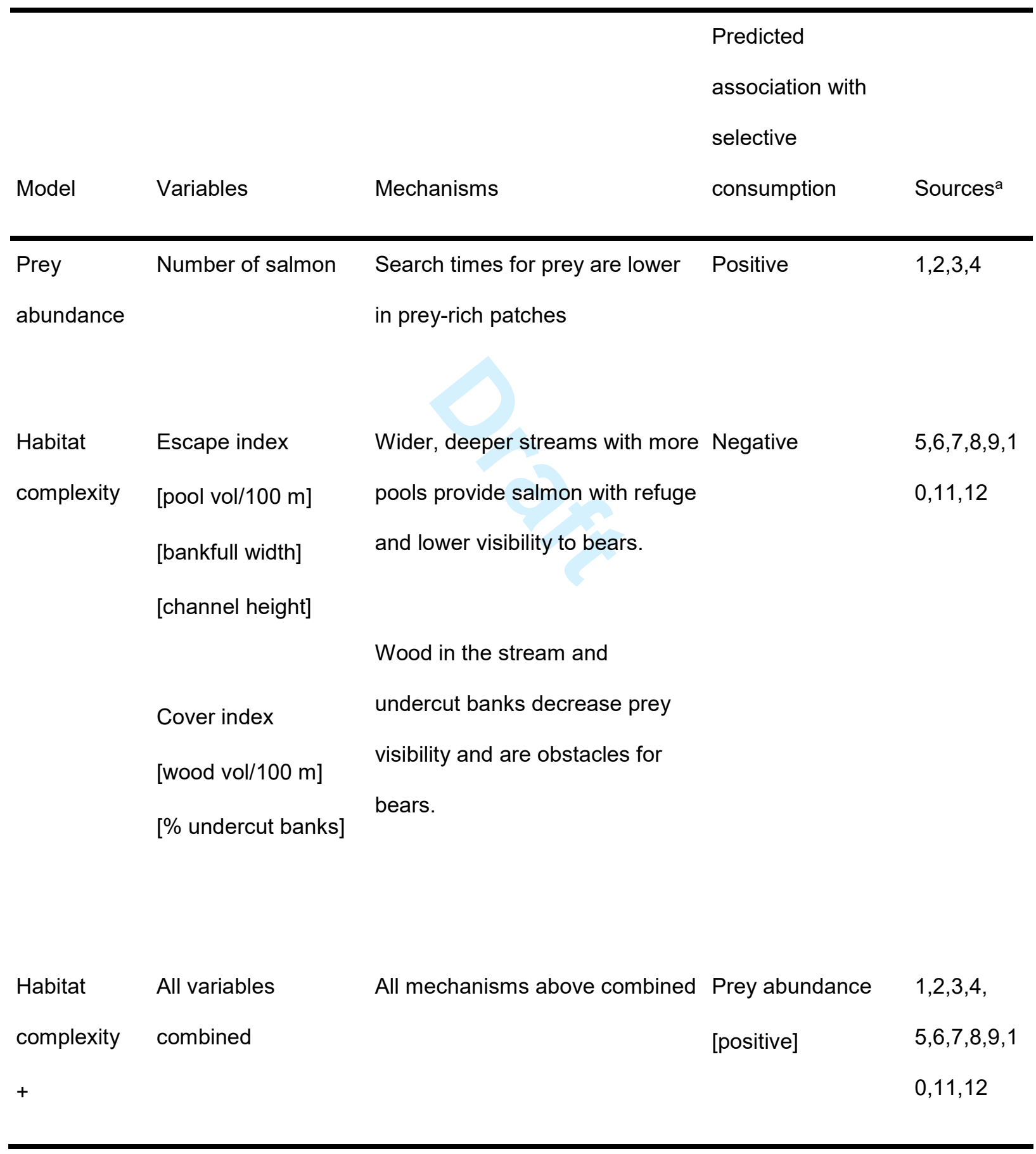


prey

Habitat complexity

abundance

[negative]

541 a Source: 1) Cunningham et al. 2013, 2) Gende et al. 2001, 3) MacArthur and Pianka 1966, 4) Quinn et al.

542 2003, 5) Gende et al. 2004b, 6) Quinn and Buck 2001, 7) Quinn and Kinnison 1999, 8) Deschênes and

543 Rodríguez 2007, 9) Fukushima and Smoker 1998, 10) Braun and Reynolds 2011, 11) Floyd et al. 2009,

544 12) Roni and Quinn 2001 
545 Table 2. Summary of stream features. "Cover index" is a principal component created with the volume of wood

546

547

548

549 per $100 \mathrm{~m}$ and percent of bank that is undercut. "Escape index" is a principal component created with mean bankfull width, mean channel height and pool volume per $100 \mathrm{~m}$. Salmon abundance, density and predation rate is calculated at the stream and predation rate is calculated according to the method described in Quinn et al. (2001).

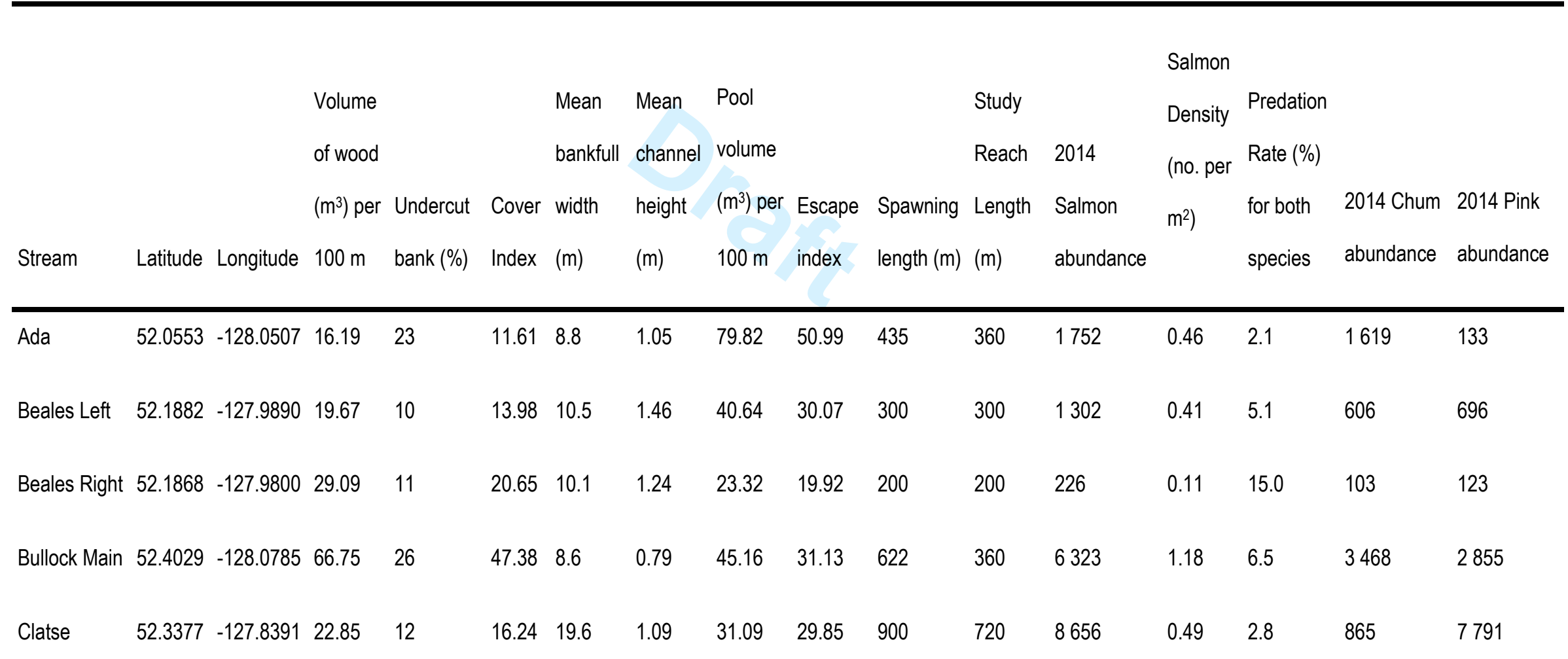




\begin{tabular}{|c|c|c|c|c|c|c|c|c|c|c|c|c|c|c|c|c|}
\hline Fancy Right & 52.0585 & -128.0167 & 32.12 & 56 & 23.12 & 4.3 & 0.77 & 22.71 & 15.86 & 298 & 240 & 290 & 0.22 & 12.3 & 287 & 3 \\
\hline Fannie Left & 52.0426 & -128.0668 & 33.49 & 31 & 23.90 & 10.7 & 0.79 & 179.4 & 108.32 & 1500 & 480 & 14019 & 0.97 & 2.27 & 8719 & 5300 \\
\hline Goat Bushu & 52.2132 & -127.8767 & 25.53 & 46 & 18.38 & 5.9 & 0.78 & 59.61 & 37.66 & 1000 & 240 & 774 & 0.13 & 22.4 & 150 & 624 \\
\hline Hooknose & 52.1249 & -127.8370 & 26.95 & 35 & 19.30 & 11.7 & 0.99 & 224.87 & 134.76 & 1800 & 600 & 2147 & 0.10 & 6.6 & 522 & 1625 \\
\hline Kill Creek & 52.4267 & -128.0958 & 62.86 & 66 & 44.91 & 3.4 & 0.48 & 1.86 & 3.33 & 543 & 120 & 1808 & 0.98 & 15.5 & 1531 & 277 \\
\hline Kunsoot & 52.1569 & -128.0435 & 52.68 & 32 & 37.48 & 14.3 & 0.66 & 36.2 & 29.34 & 1280 & 480 & 6910 & 0.38 & 5.8 & 1851 & 5059 \\
\hline \multicolumn{17}{|l|}{ Main } \\
\hline Sagar & 52.0959 & -127.8388 & 16.33 & 14 & 11.64 & 15.5 & 1.39 & 161.51 & 101.40 & 180 & 180 & 2100 & 0.75 & 3.7 & 1124 & 976 \\
\hline
\end{tabular}


551 Table 3 Comparison of mixed-effects models of selective consumption of salmon

552

553

554

555

556 carcasses by bears using Akaike's Information Criterion $\left(\mathrm{AIC}_{\mathrm{c}}\right)$, corrected for small sample size. Each model includes a random effect of site. Sex, species and date are forced fixed effects in each model to control for possible differences in selective consumption patterns according to those parameters.

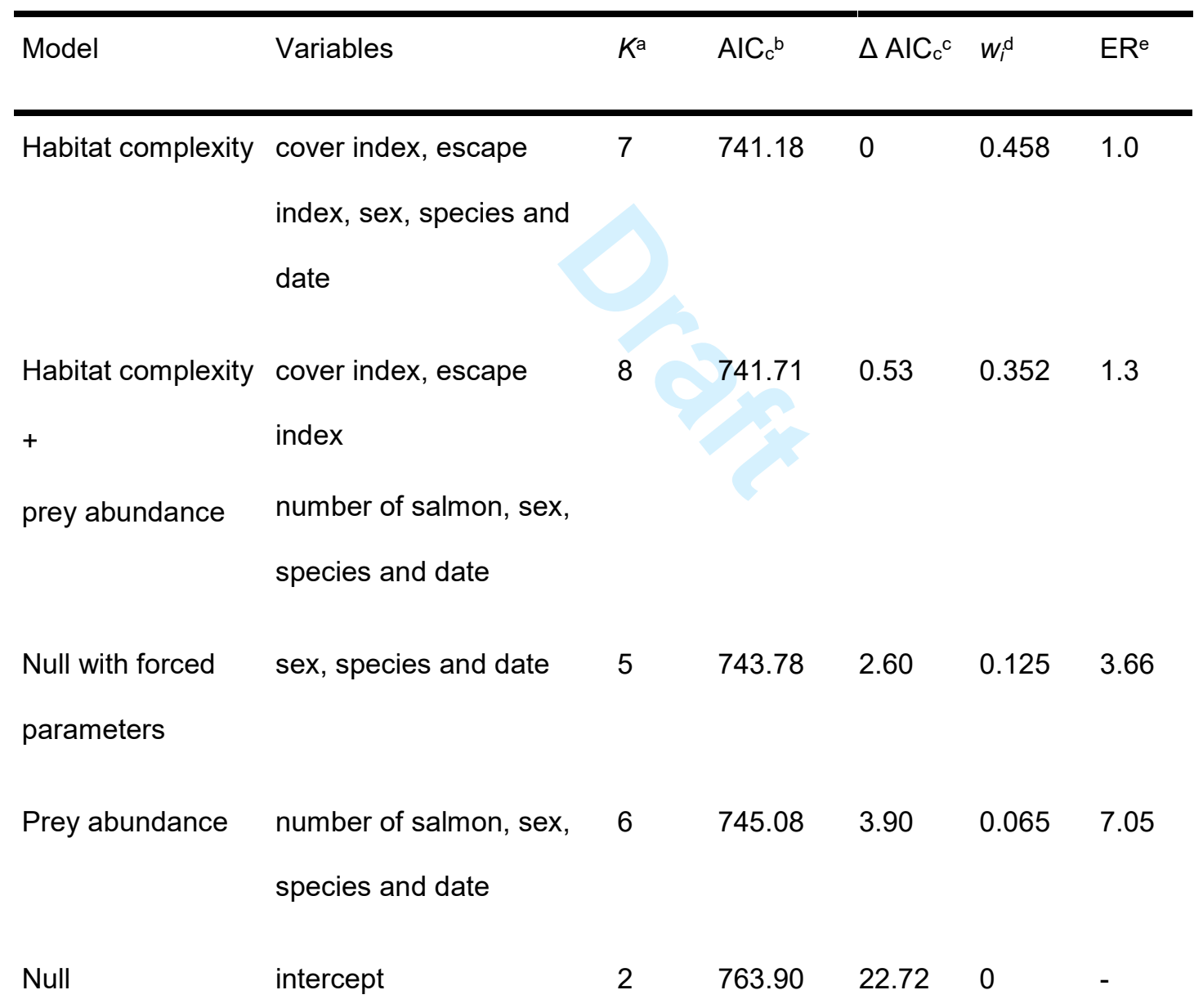

557 a Number of parameters ${ }^{\mathrm{b}}$ Model strength (lower indicates a better fit) ${ }^{c}$ Difference of $\mathrm{AIC}_{\mathrm{c}}$ value with top 558 model $\mathrm{AIC}_{\mathrm{c}}$ value ${ }^{\mathrm{d}}$ The Akaike weight; probability that it is the best model e Evidence ratio 


\section{Figure captions}

560 Figure 1 Study stream locations $(n=12)$ in British Columbia, Canada. Circles represent each stream mouth.

562

Figure 2

Relationships between the proportion of selectively consumed salmon and cover index, escape index, date (1 = 11 September 2014) and number of spawning salmon. For cover, escape and \# of spawning salmon plots, each point represents the proportion of fish selectively consumed at that stream. Each point in the date plot represents the proportion of fish selectively consumed on that survey date (streams pooled). Selective consumption by bears is defined as eggs and/or brain having been consumed and $<50 \%$ of carcass consumed.

Probability plots for the top model of selective consumption of salmon selective consumption against model variables, with other variables set to their mean value. Bands and error bars are $95 \%$ confidence intervals. 


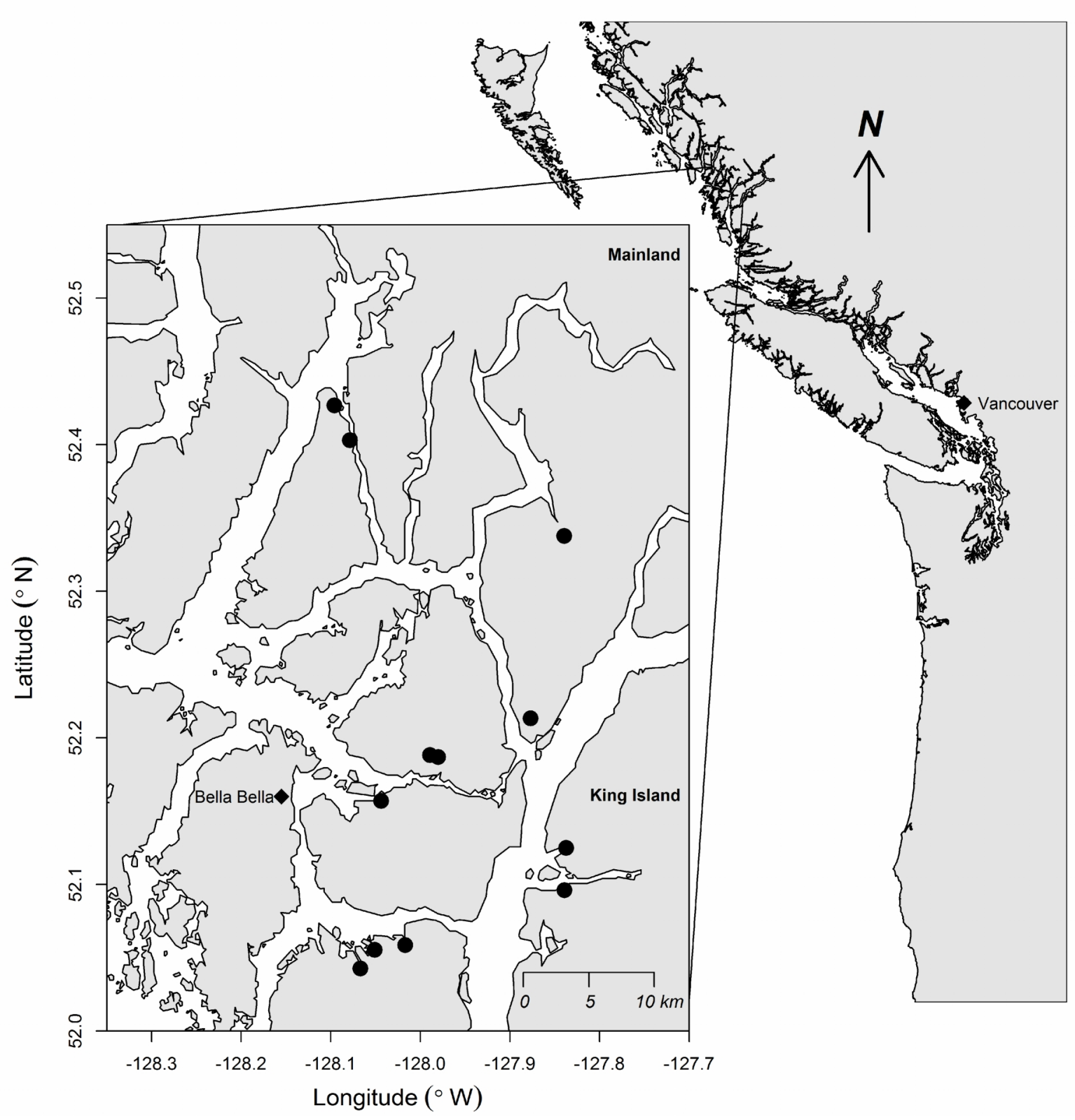

582 Figure 1 Study stream locations $(n=12)$ in British Columbia, Canada. Circles

583 represent each stream mouth. 


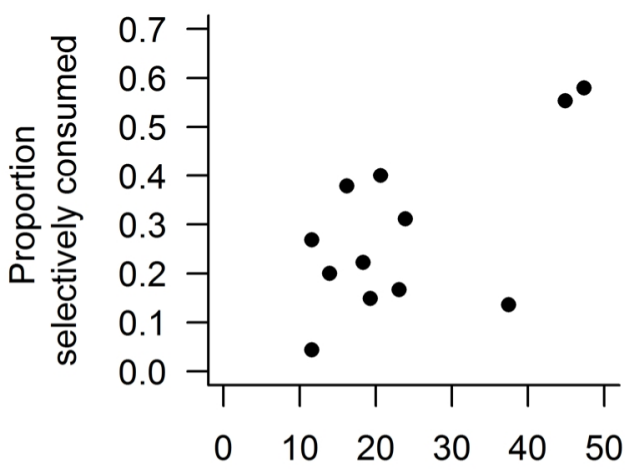

Cover index

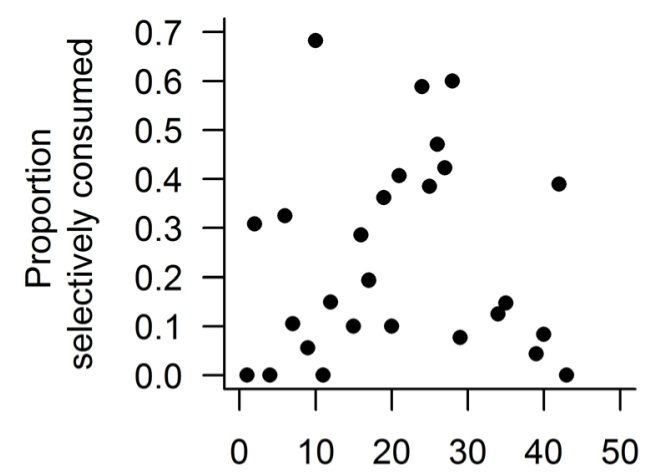

Date

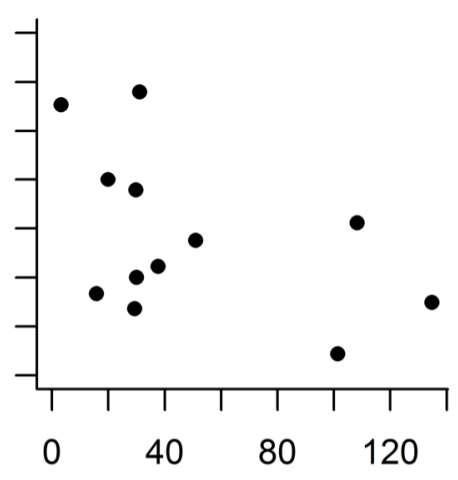

Escape index

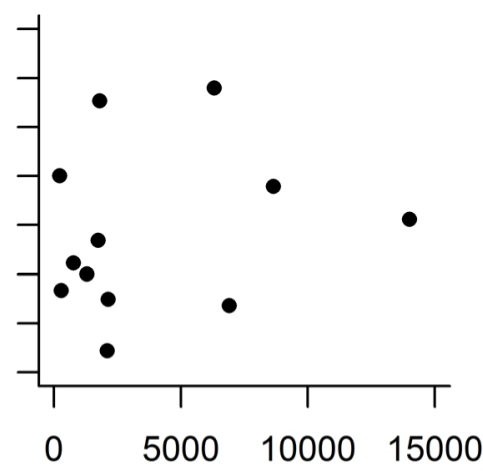

\# of spawning salmon

588 Figure 2 Relationships between the proportion of selectively consumed salmon and cover index, escape index, date $(1=11$ September 2014) and number of spawning salmon. For cover, escape and \# of spawning salmon plots, each point represents the proportion of fish selectively consumed at that stream. Each point in the date plot represents the proportion of fish selectively consumed on that survey date (streams pooled). Selective consumption by bears is defined as eggs and/or brain having been consumed and $<50 \%$ of carcass consumed. 

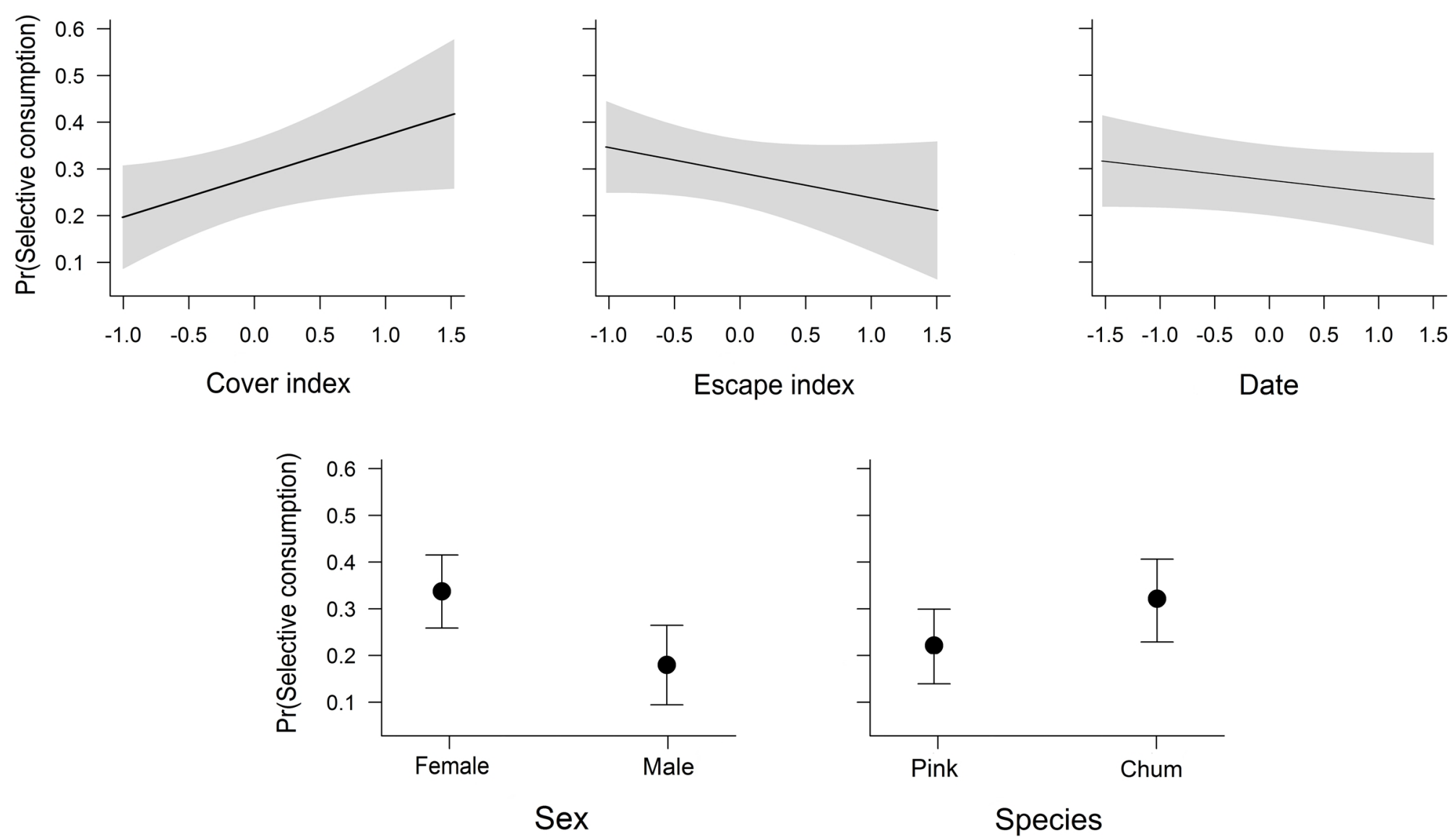

598

599 Figure 3 Probability plots for the top model of selective consumption of salmon carcasses by bears. Lines and circles 600 are predicted probabilities of selective consumption against model variables, with other variables set to their mean value. Bands and error bars are 95\% confidence intervals. 


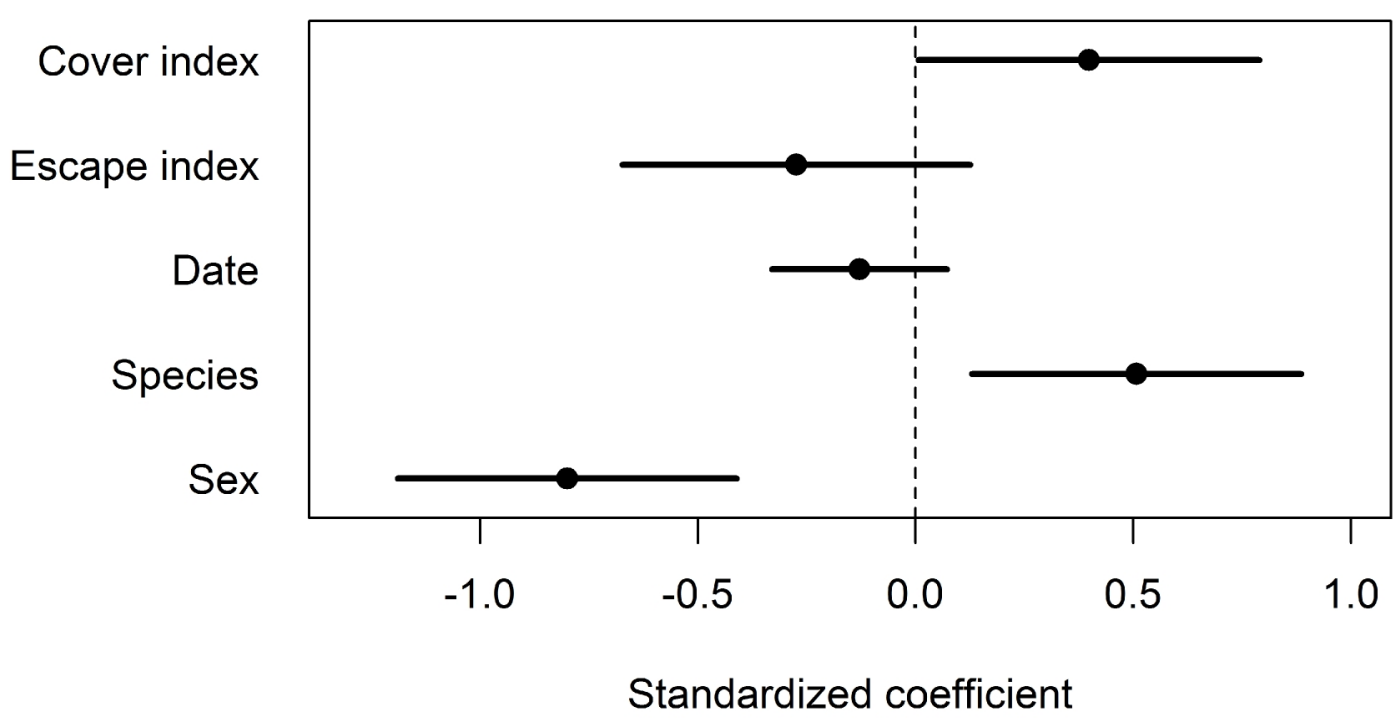

602

603 Figure 4 Standardized (mean=0, SD=2) coefficient values (circles) with 95\%

604 confidence intervals (lines) from the top model of selective consumption of

605 salmon carcasses by bears. The positive coefficient for species indicates

606 more selective consumption of chum than pink salmon and the negative

607 value for sex indicates more selective consumption of females than males. 